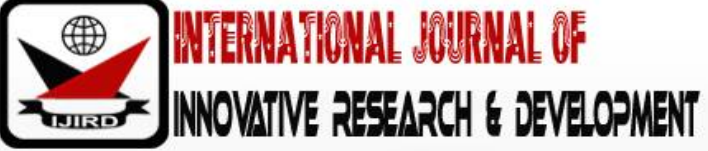

ISSN 2278 - 0211 (Online)

\section{Retaining Teachers in Rural Private Secondary Schools: Salient Roles and Best Practices of Selected School Managements}

\author{
Juvenalis Asantemungu
Senior Lecturer, Constituent College of SAUT,
Archbishop Mihayo University College of Tabora, Tanzania
Consolata Anicet
Administrative Coordinator, Department of Studies, Alliance Française of Arusha, Tanzania
}

\begin{abstract}
:
This paper assessed the contribution of school management in retaining teachers in rural private secondary schools in Tanzania. The study was guided by three objectives: to investigate the factors influencing teacher attrition in rural private secondary schools, to identify the challenges facing the school management in teacher retention in rural private secondary schools and to examine the strategies used by the school management in retaining teachers in rural private secondary schools. The study involved 35 teachers and 5 school directors in 5 secondary schools in a rural environment in Tanzania. It used focus group discussion to teachers and interviews to heads of schools as well as to school directors. The findings revealed that there are several constraints facing rural private schools including: poor living standards of the surrounding community, unfavorable school culture, lack of recognition by the school management, student age and gender that may lead to teacher attrition in rural schools. Among the major challenges facing the school management in retaining teachers in those schools included inadequate housing for teachers, poor infrastructure such as roads, water and other social services including presence of low-quality pre-school facilities. Further, the strategies employed by the school management to ensure teacher retention in rural private secondary schools included: provision of subsistence allowance to teachers on first appointment, enhancing school management-teacher relations, and establishing better school - community relationship. This study recommends that, school managements in rural private schools should ensure enough budgets for teachers' accommodation in rural areas. It is also recommended that improving working conditions and allowing flexible working hours for teachers who wish to pursue further studies would motivate teachers working in rural private secondary schools. Finally, the paper suggests that both the government, and private institutions owning schools, should take an active role in improving infrastructure and ensuring better social services in rural areas.
\end{abstract}

Keywords: Teacher retention, rural, school management, salient roles, teacher attrition

\section{Introduction}

Retaining good teachers is a global challenge for schools, particularly those in rural districts. In Tanzanian context, insufficient teachers' salaries, unconducive working environment and delays in payment of teachers' allowances may lead to teacher's dissatisfaction in their job and therefore they may decide to shift to other schools or even quit their profession. As cited in Tech-Hong and Waheed (2011), Herzberg Two Factor Theory by Frederick Herzberg (1959) argues that job satisfaction and dissatisfaction are the products of two separate factors: motivating factors (satisfiers) and hygiene factors (dissatisfiers). Guided by this theory, teacher retention in remote schools may be affected by both motivating and hygiene factors. Therefore, unfavorable working conditions may lead to teachers' dissatisfaction and as a result they may decide to quit from the school where they have been working.

Today schools operating in rural areas are the most affected by a high level of teacher attrition. A study conducted by Boniface (2016) on Teachers' Retention in Tanzanian Remote Secondary Schools, shows that teachers perceive problems related to housing, social services, conflicts in schools, the inability to influence changes in schools, the teaching and learning situation and limited opportunities as the chief reasons for not remaining in remote schools.

In some occasions, when new teachers are appointed to work in these schools, they tend to resist or sometimes those who report to their duty stations in rural areas can stay shortly then find ways of shifting to urban schools. Some of them even quit the teaching profession as expressed in Hakielimu (2000) that observes thus; "I know a teacher who decided to leave teaching when he was posted to a remote place. He was not sure how he would survive in such a remote place" (p.6). In some rural areas, the environment may affect retention of teachers in schools. Some rural secondary schools are not easily reachable especially during the rainy season because of poor infrastructure such as low-quality roads. Also, in some remote areas there is no electricity or access to potable water. This situation may not be friendly to young and newly employed teachers who have been spending all their lives in urban areas. Consequently, in order for the 
school management to cover this gap, unqualified teachers such as form six leavers may be hired to work as part time or full-time teachers in these schools.

Although the Tanzanian government has always tried to ensure that teachers are retained in rural schools, many schools in rural areas still experience acute shortage of teachers, as revealed by Kisembo (2007) on The Guardian Newspaper that claims, "the government promised to provide special incentives and priorities to teachers who work in difficult environment especially in remote schools" (p.10). This meant to attract and encourage newly trained teachers to work in rural schools. These incentives include priority to those who request professional advancement. Therefore, the school management, as a key role player in ensuring better education, tries to find different ways of attracting and retaining teachers for the purpose of attaining educational goals. Sumra (2006) as quoted in HakiElimu (2007) pointed out that although efforts are underway towards improving teachers' professional knowledge and skills, far less attention is focused on their material welfare.

This study endeavored to attain the following objectives:

- To find out factors influencing teacher attrition in rural private secondary schools.

- To identify the challenges facing the school management in retaining teachers in rural private secondary schools.

- To examine the strategies used by the school management in retaining teachers in rural private secondary schools.

The study was guided by the following research questions:

- What are the factors influencing teacher attrition in rural private secondary schools?

- What are the challenges facing the school management in teacher retention in rural private secondary schools?

- What are the strategies used by the school management in retaining teachers in rural private secondary schools?

\section{Literature Review}

\subsection{Factors Influencing Teacher Attrition in Rural Schools}

Teacher attrition varies widely between countries, this may depend on the geographical location and economic status. The studies show that in America annual teachers attrition rose by 41\% from 1987 to 2008 (Ingersoll \& Merrill, 2012). In Sub-Saharan Africa a study by Education International (2007) indicates an average teacher attrition rate of $4 \%$ in six countries; Gambia, Kenya, Lesotho, Tanzania, Uganda and Zambia. In Namibia, Kubberund (1999) reported a total teacher attrition rate of $11.7 \%$. Studies conducted by the World Bank between 2006 and 2007 found attrition rates ranging from $2 \%$ to $10 \%$ (Mulkeen 2010). Even higher teacher attrition rates are observed in countries experiencing conflict although this is rarely well recorded (UNESCO, 2007). Teacher attrition may also be caused by various factors. Frederick Herzberg (1959) as cited in Ball (2003) identifies two factors, motivating (satisfiers) and hygiene (dissatisfiers) which are intrinsic and extrinsic.

\subsubsection{Motivating Factors}

Motivating factors refer to satisfiers and are primarily intrinsic including recognition, work itself, responsibility and work environment. This means that when teachers lack recognition after a hard work, or when there is an unfavorable working environment teacher are more likely to be demotivated and therefore decide to quit from the school. According to Maslow's hierarchy of needs (Maslow,1943) one must satisfy lower level basic needs before progressing on to meet higher level growth needs. When a new teacher is appointed to work in a remote school, he/ she expects that the basic needs will be met. As long as these are fulfilled, he/ she will be longing to obtain the next according to the hierarchy of needs. Once these needs have been reasonably satisfied, one may be able to reach the highest level called self-actualization. On the contrary, a teacher may decide to shift to another place.

\subsubsection{Hygiene Factors (Dissatisfiers)}

Other factors leading to teacher attrition are called dissatisfiers. According to Herzberg (1959) these are extrinsic factors which include salary, supervision, working condition, personal life and company policy. When teachers are not satisfied with these factors, the performance may become low or sometimes teachers may decide to quit the rural school. A study conducted in Kenya by Kalai et al. (2016) the factors influencing teacher attrition include teacher's age, level of education, availability of job opportunities and teacher's discipline whereby institutional factors include teacher's workload, teacher management, head teacher's mode of supervision and working environment.

Another study was conducted in Ghana by Baah et al. (2009) which stated that the high rate of teacher turnover has been attributed to the factors such as poor working conditions for teachers. Teachers in Ghana are among the poorly paid in the public service. They continued to say that these communities often lack all the basic necessities of life such as potable water, electricity and health facilities among others. Teachers in such deprived communities generally have very little opportunity for self-development and the development of their children (Baah et al. 2009). They are sometimes compelled to work long hours and engage in multiple tasks, support and supervision. Services are lacking, facilities and resources for effective teaching are usually not available to them.

As stated by Hon. Nimrod Mkono, the Member of Parliament who represents Butiama. Butiama is a district within Mara region, in northern Tanzania, that;

In our Secondary schools, we face a very severe shortage of teachers and the government doesn't seem to be able to cope with this chronic situation. We try to partly change this situation by inviting volunteers from abroad. When you address the desperate situation of teachers in Tanzania. Good graduate teachers prefer to stay in towns and cities where 
there are better social services. Teachers in urban areas can also make more money with private tuitions (Vodacom-World Article, 2011).

This shows that teacher shortage in rural schools is a serious and global concern which should be addressed immediately. Government, private institutions and individuals are all invited to take part in this matter.

\subsection{Challenges Facing Teacher Retention in Rural Schools}

As stated in Hammer et al (2005) in their study about "Challenges Specific to Rural Districts" have identified four primary challenges faced by rural schools and districts. These are lower pay, geographic and social isolation, and difficult working conditions. In South Africa, teacher shortage in rural schools remains the biggest challenge in regard to achieving the Millennium Development Goals (MDG) (DoE, 2005; Kabungaidze, Mahlatshana \& Ngirange, 2013) as cited in Masinire (2014). In Ghana, for example, over $80 \%$ of teachers said they preferred to teach in urban schools. Also, a recent survey of 262 newly trained teachers in Ghana posted to four rural districts, showed that 115 failed to arrive at their teaching post (Baah,2009).

With regard to social isolation, Reed and Busby (1985) have stated that in rural communities with limited recreational facilities, new teachers often complain about loneliness and isolation they feel. With few social activities, new teachers can develop psychological symptoms of boredom and depression. In some cases, teachers may decide to quit the rural school.

The level of teachers' education or qualifications, has been found to be positively associated with turnover, suggesting that the more educated employees are, the more likely they are to quit. A study by Borman and Maritza (2008) pointed out that the teachers with a post-graduate degree would leave teaching compared to teachers without a graduate degree. Although in Tanzanian context, this can apply in both rural and urban schools.

However, in terms of gender and age, male teachers are likely to stay more in remote areas. Moreover, it could be generally noted from the literature that young, well- educated and experienced teachers are more difficult to retain in remote areas. Furthermore, evidence shows that when age and gender are combined, women are more likely to remain when aging than are men (Griffeth et al., 2000). It was found that the attrition rate of young teachers was about 11-13\%; for those aged 40-54, the attrition rate was only $5 \%$ and for those aged 55 and older attrition rose sharply because of retirement.

According to Ingersoll and May (2011) teacher shortages in the United States of America are not attributable only to the imbalance between supply and demand caused by large number of teacher retirements. Rather, teacher shortages, which are not in all subject areas, result from the number of teachers who move from one school to another or leave teaching profession. This shows that, teacher retention is a global challenge which may affect developed countries as well.

Most of these studies have been focusing on the challenges facing teacher retention in public schools and forgetting about private schools especially in rural areas where the problem prevails. Also, the challenges may differ from one area to another since rural area can be defined differently from one country or continent to another due to socialeconomic disparity.

\subsection{Retention Strategies in Schools Based on Rural Areas}

Teacher retention strategies may vary from one school to another due to the big difference in geographical locations. Also, there is a great disparity between the working conditions of rural and urban schools and the learning and teaching experiences they offer. This is because education policies have an urban-bias in that they are formulated to meet the demographic profile, settlement patterns and the resource base of urban areas (Department of Education, 2005).

Retention strategies have been discussed by various scholars in different studies. Some of the strategies include increased teacher remuneration which addresses the pull of alternative employment as stated by Mulkeen (2010); Jarousse et al (2009) and Chapman (1994). When teachers are well paid, they get motivated and therefore encouraged to continue working for the school. A study conducted by Manhertz (2011) suggests some key strategies for employee retention such as offering competitive salary, benefits, and incentive packages. Schools should provide compensation and benefits commensurate with position.

In terms of working conditions, Kisembo (2007) in an article in the Guardian Newspaper, said that "the Tanzanian government promised to prevent shortage of teachers in many of southern regions in Tanzania including Mtwara and Lindi within a short period whereby this problem would be solved basing on the government strategy of improving teaching and learning environment as well (p.5). It seems that working conditions in rural schools is a very sensitive issue in which the government has to take action immediately.

Mentoring and induction programmes. According to Mulkeen (2010); Cooper and Alvarado (2006) and Chapman 1994)) when a school provides mentoring and induction programs for new teachers, this results in lower rates of staff turnover. This strategy may be effective depending on the geographical location and status of a school.

Another strategy is commitment, according to Chapman (1994) in order to ensure teacher retention in rural schools, the school management should recruit individuals with higher initial commitment to teaching, determined through an admission interview at the time the individuals apply to enter into teacher training programme. This can apply in public schools where teachers are posted to their working station after completing their training.

Grow-your-own approach. According to Beesley et al (2008) this approach refers to training local people who are most likely to return to the area and fill a need. Some examples of this approach include: a) providing additional training to paraprofessionals; b) retraining service-oriented people (e.g. military and Peace Corps); and c) partnering with teacher preparation programs and institutions of higher education to provide alternative access to coursework. When it comes to 
Tanzanian context, it seems that many people wish to remain in urban areas after completing their studies, this is due to life hardships in some rural areas.

Targeted incentives, this strategy includes salary increment and scholarship programs, as well as location-specific incentives (affordable housing, transportation, access to professional development), (Beesly, 2008). According to the study, these can act as motivators to teacher retention as stated in Nipashe newspaper (2007) that has noted that "The Tanzanian government promised to provide some special incentives to teachers who work in difficult working conditions especially in villages" (p.10). This will involve a special consideration for teachers who request professional development opportunities. Despite this promise, schools in remote areas today are still experiencing shortage of teachers due to the teachers' mobility.

Boniface (2016) conducted a study on 'Teachers' Retention in Tanzanian Remote Secondary Schools - Exploring Perceived Challenges and Support" and discussed about a number of strategies towards attaining teacher retention. First, in order to attract and retain an adequate number of quality teachers, the strategy was to create an environment for the development of a well grounded, motivated and committed teaching force. To achieve this strategy, a number of targets were set, including: first, creating and supporting a conducive environment for teachers through community sensitization and mobilization by 2009; second, establishing and operationalizing a reward system for good practice for teachers and student teachers in science, mathematics and language subjects by 2009; third, reviving and strengthening the teacher parent relationship, school committees/ boards to support teachers especially in remote, rural and difficult areas by July 2009; fourth, introducing fee exemption for candidates studying science and mathematics by July 2009; fifth, strengthening continuous career guidance and counseling for schools and colleges by 2009; and sixth, introducing an attractive incentive package for teachers at all levels with special consideration of those in difficult environments by 2009.

These strategies stated by Boniface (2016) were established in order to support and improve teacher retention in public schools in Tanzania, according to this study nothing has been done with regard to improving teacher retention in private schools especially those who are working in rural areas. For example, introducing an attractive incentive, a bonus of $50 \%$ of a teacher's salary, this strategy would work well with both public and private schools operating in rural areas.

Various studies have been conducted on retaining teachers in rural areas. As demonstrated by the various literatures reviewed in this paper, many of these studies were done in developed countries. For example, Renewing Regional and Rural Teacher Education Curriculum (RRRTEC) (2008-2011) which addressed the problem of teacher shortage in rural and remote areas, conducted in Australia. Another study by Hammer et al (2005) was conducted in Virginia and revealed five major strategies for recruiting and retaining teachers. The findings of these studies in one way or another cannot be fully relevant or applicable to Tanzanian rural schools' contexts due to economic and geographical differences.

Despite these studies, remote schools in Tanzania are still facing difficulties in retaining teachers which results to shortage of workforce in the affected areas. As shown in the study conducted by King (2013) in Mbeya Tanzania, there is lack of congruence between the students and the number of teachers available. This has had a serious impact on the results of 2009, 2010, 2011 and 2012 in the national examinations. The fourth regime of the government introduced a policy of one secondary school per ward. This effort led to the establishment of about 3000 secondary school in the country.

\subsection{Ways to Improve Teacher Retention}

Various studies have proposed different ways of improving teacher retention. According to the study conducted by Buchanan et al (2013) it has been argued that collegiality and support could improve teacher retention. When experienced colleagues share their expertise and their resources generously, Early Career Teachers hear how other teachers cope with the demands of the job. This collegiality can serve as a morale-booster to newcomers, both in terms of new knowledge, insights and perspectives gained, and in terms of a welcoming gesture to the profession and to the school.

Another strategy is to assist Early Career Teachers (ECTs) with issues of retention and recruitment by understanding and appreciating their reasons for becoming a teacher, including their background and their own schooling (Buchanan et al. 2013). According to Cockburn (1999) "this understanding, together with a genuine spirit of consultation and collaboration might raise the morale of the profession as well as induce the more disillusioned to remain" (p. 235).

However, in 2007, the government created a room for form six leavers to join teachers' colleges for three months in order to fill the gap of the shortage of teachers in secondary schools. In late 2008, the teachers who attended short course for bridging the gap were required to go to colleges for further studies. The mandatory further training of these teachers necessarily increased the gap of teachers in secondary schools. Some schools, had only one teacher, and most of them had less than five teachers in the entire school (Hakielimu, 2009).For example, Ndonga primary school in Nyasa district remained with one teacher when 6 teachers decided to go to college and to university for further studies where by some of them came back after 2 years and others after 3 years.

Most of these studies have focused on the role of the government and forgetting about the role of the school management in ensuring teacher retention in rural private schools especially in rural environment where the problem prevails. Also, the factors influencing teacher attrition in rural areas, challenges and retention strategies may vary according to geographical locations. This means that, rural areas in developing countries may not be defined similarly to those in developed countries. That is why this study focused on the contribution of the school management in ensuring that teachers are encouraged to remain in rural private schools. It will also be a way forward to bring back the value of private schools operating in rural areas because they also provide education to the Tanzanian public. This is because from 1990's and back, there were very few private classes in Tanzania. 


\section{Methodology}

This study used qualitative approach focusing on analyzing a small number of events or conditions to help understand issues within the context of real life. This approach enabled the authors to understand the perceptions, feelings as well as studying emotions and attitudes of teachers in a natural setting. A descriptive design was applied for qualitative inquiries in order to facilitate the description of the real situation as it happens at the rural private secondary schools. The study was guided by two theories, Herzberg's Two-factor theory which describes two factors that can lead to job satisfaction and dissatisfaction and Maslow's hierarchy of needs theory which describes the different levels of satisfaction, this is because working in rural areas requires a certain level of satisfaction.

\subsection{Sample}

The study employed a sample of 30 teachers, 5 school heads and 5 school directors.

\subsection{Data Collection}

The data were collected by using various research instruments. These included interview guides used to run face to face interviews to school heads and school directors. This was because these are the key education stakeholders who could provide in-depth information about the problem under study. Also, focus group discussions were conducted to groups of teachers who were assuming leadership roles at school, these included academic master/ mistress, second master/ mistress, discipline teacher as well as heads of departments. The various documents reviewed included teachers' roster, teachers' personal records and transfer records in the schools so as to get information about the real situation of the actual number of teachers as well as those who left the school. The data were analysed by using qualitative content analysis based on the research questions through establishing the existence and frequency of concepts most often represented by words or phrases.

\section{Findings}

Teacher retention in rural schools has more often been of a serious concern since some schools in the rural areas experience teacher shortages. This situation may lead to overburdening of some teachers or even affect the academic performance of the students. The study found out that 2 schools in the rural areas decided to hire form six leavers to fill in the teachers' shortfall. The paper presents the findings based on the research objectives.

\subsection{Factors influencing Teacher Attrition in Rural Private Secondary Schools}

This study found that 24 teachers had negative perceptions toward rural private school environment due to poor working conditions and poor living standards in rural areas. This could be one of the factors that could make teachers less eager to work in such environment. According to Herzberg's Two-factor theory, factors that lead to job dissatisfaction are primarily extrinsic factors, which include working conditions (Robbins, 2009) as cited in Tech-Hong and Waheed (2011). Therefore, if teachers are not satisfied with the working environment, they are more likely to quit the job.

It was revealed 26 teachers were more likely to quit from rural schools whenever they had an opportunity to get a job in town. This situation was a result of job dissatisfaction as stated in the Maslow's hierarchy of needs theory that one must satisfy lower level basic needs before progressing to meet the higher level. But if the basic needs are not fulfilled a teacher may decide to shift to another place. Other teachers said that they had often been thinking of quitting rural schools but due to lack of employment in urban schools made them remain working in rural schools. Also, it was noted that, some teachers left their families in town in order for them to live and work in rural schools just because of the poor living standard in rural areas, such as Nyankanga ward, in Butiama district. 18 teachers stated that they thought of moving to town, especially in big towns because of life hardships in rural areas. If they had a chance they would love working in urban areas. They added that, rural areas are not bad, but poor infrastructure makes rural environment to be challenging.

Also, the study found that 12 teachers would love to live with their families in rural areas provided that they would find better and quality education for their children. 6 teachers did not want to shift with their families to rural areas because of poor quality education for their children especially at the kindergarten level. In some rural areas, there were no social and recreational activities that could help children to grow both morally and spiritually compared to urban areas. According to Collins (1999) social, cultural, and professional isolation may be reasons for losing rural teachers. Some teachers who work in rural schools opt to leave their families in urban areas where children can access recreational activities such as holiday camps as well as better schooling. Therefore, the government, religious institutions as well as individuals should extend social and recreational services in rural areas. This will enable children living in these areas to acquire better education and therefore to prepare them for the next level of education.

Besides, the findings indicated that poor health services influenced teacher attrition in rural schools. 24 teachers stated that sometimes it was difficult to access better health services in rural areas due to poor infrastructure. This corresponds to the findings by Mulkeen (2005) who has stated that any trip away from the rural area, to visit a doctor, collect pay, engage in in-service training, or visit family may involve long journeys and involve missing school activities. Remote areas need improved health services because these are among the fundamental human rights. According to the Universal Declaration of Human Rights of 1948, Article 25 everyone has the right to a standard of living adequate for the health and well-being of himself and of his family, including food, clothing, housing and medical care and necessary social services. Therefore, the government and private institutions should ensure improved health services in remote areas.

This study found that some organizational culture was not pleasant in rural private schools, for example in Busegwe secondary school which is a religious owned school, it was found that all teachers and non teaching staff were required to attend religious ceremonies organized by the school management. According to Bush and Anderson (2003) 
culture refers to the "values, beliefs and norms of individuals in the organisation" and is "manifested by symbols and rituals rather than through the formal structure of the organisation" (p.29). Some private schools, especially those that were owned by religious organizations, had a tendency of emphasizing on the participation of all employees and students in the beliefs of their religion as stated by Jahangeer (2004) that the Annual School Mass is an occasion where all the pupils participate, even the non-Catholic pupils.

This study observed that organizational culture may vary from one school to another according to the nature of the environment as well as the preferences of the founders of the school. Certain cultures in our working places may be unattractive to some of new recruited teachers. For example, religious owned schools have their culture in which students and teachers have to abide. Although this can apply in both rural and urban schools but some church owned schools have strong culture starting with dressing style and other practices which oblige teachers and students to participate regardless of their respective religion. For example, a teacher on duty may be obliged to attend fellowships with students for supervision. This can be a challenge to new teachers who cannot cope with this situation.

Regarding teacher development, 24 teachers stated that the school management should allow flexible working hours for its teachers who pursue further studies. Mafora (2013) has stated that it is common for teachers to miss out on staff development opportunities because of the long distance they may have to travel. Therefore, the school management should establish flexible working hours for teachers who continue with higher studies and particularly for those who are doing distance learning. Failure to do this may discourage teachers and therefore lead them to think about quitting rural schools.

\subsection{Challenges facing the School Management in Retaining Teachers in Rural Private Secondary Schools}

According to this study 4 school heads stated that inadequate housing for teachers in rural schools was a challenge. This is because when a new teacher arrives in a rural school, he/ she expects to find accommodation available for him/ her when starting a new life. Education for All Global Monitoring Report (GMR) stated that trained teachers should be encouraged to accept positions in areas where they are most needed through appropriate working conditions, and a combination of incentives, such as good housing and extra allowances or bonuses. Therefore, offering accommodation to newly employed teachers would make them warmly welcomed. Whenever there was no house for a teacher, he/ she may decide to go back home and continue searching for a job elsewhere.

Also, the study revealed that demographic characteristics such as age, marital status and gender had greater impact in teacher retention in rural private secondary schools.

Age; the author asserted that young teachers had tendency of quitting the school abruptly once they were attracted and promised better payment somewhere else. Also, young teachers in private schools were always looking for greener pasture and therefore moving from one school to another. This was a challenge for the school management because regular changing of subject teachers affects students' academic performance. The study showed that 22 teachers working in 5 rural secondary schools were below 35 years old. It was stated that if the school management would be able to get prior information it could prepare to recruit another teacher in advance in order to replace the one who is quitting. So, when a teacher quits abruptly it takes time to find another teacher who can take over the teaching responsibilities of the one who has left.

On the side of gender, this study reveals that most of the private secondary schools in the district have less number of female teachers 7 compared to males 33. The study proved that Pelazia secondary school had only a team of male teachers. This does not mean that female teachers were not applying for teaching jobs in those schools, but some of them quitted from the schools after a short period of time. For example, in Busegwe secondary school, 2 female teachers quitted the school after one month. Various reasons are associated to this behaviour. For example, in most cases, when female teachers in rural schools get married to men living in urban areas, they quit the rural environment. Also, the study revealed that female teachers endured less the challenges in the rural areas compared to men especially when working in remote schools.

Poor infrastructure in rural areas such as roads, shortage of water and lack of electricity were stated as challenges to teacher retention in rural schools. The study showed that there weren't enough tarmac roads in rural areas, therefore, during rainy season it was difficult for a person to move from one place to another because the roads were impassable

Furthermore, the study found that poor management support for career development led teachers to quit from rural private secondary schools. The study shows that 18 among 30 teachers were more likely to quit from rural schools if they missed career development support.

\subsection{The Strategies Used by the School Management in Teacher Retention in Rural Private Secondary Schools}

Various strategies are used by the school management to ensure teacher retention in private secondary schools situated in remote areas. This is due to the fact that the management of the private schools has direct mandate to employ and retain teachers.

The findings in this paper pointed out that Busegwe secondary school was providing accommodation to 3 employed teachers. This is because when a new teacher arrives in a rural school, he/ she may face some difficulties in finding accommodation, therefore in order to overcome this problem a new teacher may be provided with some allowances such as a $70 \%$ or an advance of his/her salary in order to enable him/her to settle. In most cases, newly employed teachers especially young teachers arrive to their duty stations empty handed therefore they need support. Providing accommodation and other subsistence allowances would be a better way of improving teacher retention in rural schools especially for newly employed ones. 
According to the study conducted in rural private secondary schools within Butiama district, 5 school directors asserted that in order to retain teachers in rural private schools, the school management tried to establish good relationship with its employees especially teachers. When the school management doors are open for teachers, they would be freer to express their feelings than when they are denied such an opportunity. The school management should avoid cumbersome procedures when teachers face difficulties in their working places. According to This is due to the fact that, the relationship between the organisation and its members is influenced by what motivates them to work and the rewards and fulfillment they derive from it (Mullins, 2005). Hence, enhanced close relationship with teachers should be maintained in schools as a strategy to ensure teachers retention.

Additionally, involving teachers in decision making was stated to be one of the best ways of retaining teachers in rural areas. 5 school directors and 5 school heads said that in most of the time the school management involved teachers in making decisions regarding various development issues in their schools. They also added that, in some cases, all teachers cannot be involved in decision making. Instead, only the school management team sits and discusses about the issue. As stated by one of the school heads, that;

In some cases, all teachers cannot be involved in decision making. Instead, only the school management team sits and discusses about an issue.

This is because, teachers were feeling being part of the school progress through sharing their ideas and expressing their feelings. For example, sometimes teachers need to discuss about how to improve student's performance through extra classes. Participation of teachers in decision making has many benefits. According to Wadesango (2011) participation in decision-making nurtures teachers' creativity and initiative thereby empowering them to implement innovative ideas. Participation in decision making also improves the quality of management's decisions since there is greater diversity of views and expertise as inputs to decision making. Therefore, teachers should be involved in decision making regarding matters related to school progress or teacher and pupil development. This situation makes teachers to feel considered and trusted, and therefore wish to continue working for that particular school

Finally, the authors observed that the school management of Pelazia private secondary school in Butiama district, was working closely with the community in enhancing teacher retention. For example, members of the community were involved in looking for a house for a new teacher. It was stated that in order to nurture that relationship, when there was a surplus of food, the school management shared it with the needy members of the school community.

\section{Summary and Recommendations}

The findings can be summarized as follows:

- It has been revealed that the various factors that lead to teacher attrition in rural private schools are such as: poor living standards in rural areas, unfavorable school culture, lack of recognition by the school management, age and gender

- Among the major challenges facing the school management in retaining teachers in those schools included inadequate housing for teachers, poor infrastructure such as roads, water and other social services including presence of low-quality pre-school facilities.

- Furthermore, the strategies employed by the school management to ensure teacher retention in rural private secondary schools were such as: provision of subsistence allowance to teachers on first appointment, enhancing school management-teacher relations, and establishing better school - community relationship.

On the basis of these findings with regard to the main research questions, the study recommends the following:

- It is recommended that newly employed teachers should be supported once they report in rural private schools particularly on the aspect of accommodation and subsistence allowance

- Also, the school management should plan for financial support so as to enable teachers to attend seminars and training regarding education issues. According to Mullins (2005) training is therefore a key element of improved organisational performance. Training increases the level of individual and organisational competence. It helps to reconcile the gap between what should happen and what is happening - between desired targets or standards and actual levels of work performance (p.757).

- Education stakeholders should be involved in order to ensure better working environment in rural private schools. For example, the government should ensure improved infrastructure such as roads, water and electricity in rural areas.

- The school management in private schools especially in rural areas should allow participation in extra-curricular activities as well as recreational activities taking place in both rural and urban areas.

- Finally, the school owners should establish flexible rules and regulations about religious matters in working places as well as giving freedom to teachers and other staff to decide whether or not to participate in certain religious practices

\section{Conclusion}

This study focused on private schools in one district and has revealed many challenges and issues. The state of private schools in the district may be representative of what exists also in similar districts in the country. The conclusions are, therefore, the following;

There is a need of making follow up on the conditions in which these schools operate to ensure better working environment in rural schools. Regular visits by education officers would be needed in private schools regardless of how remote they are. Also, education stakeholders should be involved in various aspects regarding education development in rural private schools. A similar study could be replicated to cover a large sample in different regions to determine teacher 
retention strategies in rural private schools. This is because rural areas in Tanzania may differ from one region or district to another.

\section{References}

i. Baah, Y., Otoo, K.N., \& Osei-Boateng, C. (2009). Teacher Attrition in Ghana. Retrieved From htttp// eiie.org/docs/webdepot/gnat on June 23,2017Ball, J. (2003). Understanding Herzberg's Motivation Theory. Retrieved from: http:/ / www.chinaacc.com/ upload/ html/ 2013/ on January 9, 2017

ii. Beesley, A., Atwill, K., Blair, P., Barley, Z. (2008). Strategies for Recruitment of Secondary School Teachers in Central Region Rural Schools. Denver. Retrieved from http:/ / files.eric.ed.gov/ fulltext/ on August 42017

iii. Best Start Resource Centre (2010). How to Reach Rural Populations. Toronto, Ontario, Canada. Retrieved from http:/ / www.beststart.org/ resources/ howto/ pdf on February 202017

iv. Boniface, R. (2016). Teachers' Retention in Tanzanian Remote Secondary Schools - Exploring Perceived Challenges and Support. Sweden: Linnaeus University Press. Retrieved from https://www.diva-portal.org/ on January 10, 2017

v. Borman, D \& Maritza. N. (2008), Teacher Attrition and Retention: A Meta-Analytic and Narrative Review of the Research. Retrieved from https:/ / www.jstor.org/ stable/ 40071133

vi. Buchanan, J., Prescott, A., Schuck, S., Aubusson, P., Burke, P., \& Louviere, J. (2013). Teacher Retention and Attrition: Views of Early Career Teachers. Australian Journal of Teacher Education, Retrieved from: http: www// dx.doi.org/ on March 2, 2018

vii. Bush, T. and Anderson, L. (2003). Organisational culture. London, Commonwealth Secretariat. Chapman, A. (1994) Managing Today and Tomorrow. Volume: 14 issues: 2, page(s): 67-68. University of Durham Retrieved from: https:/ / doi.org/ 10.1177/ 014473949401400206

viii. DoE (2003). Towards School Management and Governance. Guide for School Management Team. Pretoria.

ix. Education for All Global Monitoring Report (2015). Retrieved from http:// unesdoc.unesco.org/ images on September,20 2017

x. Griffeth, W. and Hom, P. And Stefan, G. (2000) A Meta-Analysis of Antecedents and Correlates of Employee Turnover: Update, Moderator Tests, and Research Implications for the Next Millennium. Volume: 26 issue: 3, page(s): 463-488Retrieved $\mathrm{f}$

xi. Habari Leo (2007). Upungufu wa Waalimu.Tanzania

xii. HakiElimu (2007). Ahadi za Serikali III. Dar es Salaam.

xiii. HEART (2013). Attracting and Retaining Teachers. Retrieved from http://www.heart-resources.org/wp on August 42017

xiv. Howley, A., Rhodes, M. \& Beall, J. (2009). Journal for the Education of the Gifted

xv. .Vol. 32, No. 4, 2009, pp. 515-536. Retrieved from http:/ / www.prufrock.com on March 20, 2017

xvi. Ingersoll, R., \& May, H. (2011). Recruitment, Retention and the Minority Teacher

xvii. Shortage. Retrieved from http:/ / repository.upenn.edu/ gse pubs/ 226 on February 11, 2017

xviii. Jahangeer, S. (2004) School Culture in a Private Secondary Institution in Mauritius: International Education Journal, Vol 5, No 2, 2004: Retrieved from: http:/ / iej.cjb.net on June 29, 2017

xix. Kalai, J.M. (2016). Factors Influencing Teacher Attrition. International Journal of

xx. Education and Research. 2016; Vol. 4 No. (3):367-382. Retrieved from

xxi. https:/ / profiles.uonbi.ac.ke/ on March 272017

xxii. King, N.A. (2013) Investigation of Factors Hindering Quality Education in Secondary Schools in Mbeya, Tanzania. Retrieved from https:/ / www.researchgate.net/ publication/313292752_on March 20, 2017

xxiii. Kisembo, P. (2007). Tanzanian Government Support to Teachers. The guardian

xxiv. Newspaper. Tanzania.

xxv. Mafora, P. (2013). Managing Teacher Retention in a Rural School District in South Africa. Pretoria. Retrieved from https:/ / eric.ed.gov/ on January 17, 2017

xxvi. Manhertz, H (2011). Worldwide Trends in Employee Retention. Retrieved from https:/ / achieveglobalmec.files.wordpress.com on December 11, 2016

xxvii. Masinire, A. (2014). Recruiting and Retaining Teachers in Rural Schools: Insights from a Rural

xxviii. Teaching Experience Programme. South Africa. Retrieved from www.researchgate.net/ publication on June 29, 2017

xxix. McLeod, S. (2014). Maslow's Hierarchy of Needs. Retrieved from: http:/ / www.simplypsychology.org/ maslow.html on May 2, 2017

xxx. Mullins, L. J. (2005). Management and Organizational Behavior (7th ed) Prentice Hall: London

xxxi. Mulkeen, A. (2005). Teachers for Rural Schools. A Challenge for Africa. African Regional World Bank. Retrieved from www.ayalaconsulting.com.ec on February 12, 2017

xxxii. Mulkeen, A. \& Crowe-Taft, N. (2010). Teacher Attrition in Sub -Saharan Africa. Retrieved from www.teachersforefa.org on February 10, 2017

xxxiii. Reed, D.F \& Busby D.W. (1985). Teacher Incentives in Rural Schools. Research in Rural Education, Volume 3. Retrieved from: http:/ / jrre.vmhost.psu.edu on March 11,2017

xxxiv. Saad, T. U \& Sadiq, A. M. (2014). The Relevance of School Community Relationship on the Development of Primary Education. Journal of Research \& Method in Education. Retrieved from www.iosrjournals.org on July 8, 2017 
xxxv. Sumra, S. (2006). The Living and Working Conditions of Teachers in Tanzania. HakiElimu Tanzania. Retrieved from: http:/ / old.ei-ie.org/ healthand safety/ file on May 2, 2017

xxxvi. Tech-Hong, T. \& Waheed, A. (2011). Herzberg's Motivation-Hygiene and Job

xxxvii. Satisfaction in the Malaysian Retail sector: Mediating Effect of Love of Money.

xxxviii. Asian Academy of Management Journal, Vol. 16, No. 1, 73-94, Retrieved from https:/ mpra.ub.uni-muenchen.de/ on February 2,0 2017

xxxix. Universal Declaration of Human Rights (1948). Retrieved from http://www.un.org/ en/ universal-declarationhuman-rights/ .on September 30, 2016

xl. Vodacom-World Article (2011) Musoma Rural Educational Project: Tanzania. Retrieved from www.musomarural.org on October 29, 2017

xli. Wadesango, N. (2011). The Influence of Teacher Participation in Decision-making on Their Occupational Morale. Republic of South Africa. Retrieved from: http:/ / www. Krepublishers.com/ 02-Journals on February 21, 2017. 